\title{
EXPERIMENTAL INVESTIGATION OF EFFICIENCY OF PLAIN WEFT KNITTED FABRIC LAYERED REINFORCEMENT IN FIBERCONCRETE
}

\author{
Galina Harjkova ${ }^{1}$, Vitalijs Lusis ${ }^{2}$, Andrejs Krasnikovs ${ }^{3}$ \\ 1,3Institute of Mechanics, Faculty of Transport and Mechanical Engineering, Riga Technical University, \\ Ezermalas Str. 6k, LV-1006 Riga, Latvia \\ ${ }^{2}$ Faculty of Civil Engineering, Riga Technical University, Azenes Str.16/20, LV-1048 Riga, Latvia \\ ${ }^{3}$ Concrete Mechanics laboratory, Riga Technical University, Azenes Str.16/20, LV-1048 Riga, Latvia
}

E-mail: ${ }^{1}$ galina.harjkova@rtu.lv (correspondingauthor); ${ }^{2}$ vitalijs.lusis@rtu.lv; ${ }^{3}$ krasnikovs.andrejs@gmail.com

\begin{abstract}
Reinforcing cement-based composites with continuous fibers is one of the most efficient ways to obtain high performance materials. This paper studies the application of layers of knitted textiles with relatively simple fabric architecture used to strengthen fiberconcrete beams. The objective of this study was to evaluate glass knitted fabric as reinforcement for fiberconcrete. For this purpose fiberconcrete beams with textile reinforcement in the form of three plies of glass weft knitted fabric (jersey) were produced. Four point bending test was used to experimentally investigate the influence of textile plies on composite flexural strength. The obtained results were compared with the material without textile reinforcement. The fiberconcrete reinforced by textile layers showed better flexural performance compared to nonreinforced fiberconcrete samples.
\end{abstract}

Keywords: Textile reinforced concrete (TRF), cement composites, fiberconcrete, knitted fabric reinforcement, weft knit, flexural strength

\section{Introduction}

Cementitious matrices are brittle. Such materials may be reinforced by steel fibers with various geometry, glass, synthetic or natural fibers (ACI Committee 544 1997) and textiles.

In the case of cementitious composites reinforced by curved continuous fibers, a wide variety of fabric types and textiles can be used - non-woven, braided, woven and knitted fabrics, some of them were studied by different authors: Peled, Bentur 2000, Krüger et al. 2001, Peled et al. 2008, Peledet al. 2009. Fibrous reinforcement become effective mainly after the matrix has cracked and fibers are bridging the crack in such a way improving material load bearing capacity.

In the fabric form, an orientation of the yarns can be controlled and every single yarn itself can be made out of single or multifilaments. Textile reinforcement consists of continuous fibers comparing to ordinary short fiber reinforced concrete and therefore fabric may provide mechanical anchoring, which is induced when the concrete penetrates in the openings in the fabric, these materials also exhibit superior tensile strength and ductility in comparison to other discrete fiber reinforced concrete composites (Pakravan et al. 2011). The properties of cementitious composites reinforced by fabrics are expected to depend not only on the properties of the reinforcing material and its content, but also on the geometry of the fabric (Peled, Bentur 1998).

The scope of this investigation is a fiberconcrete reinforced with layers of knitted fabrics. Knitted fabrics have high degree of deformability and near-net structure. Till now, knitted textiles for cement-based composites were used mainly in the form of warp-knitted fabric (Krüger et al. 2001, Peled et al. 2009) or weft insertion warp-knitted fabric (Peled, Bentur 1998, Peled, Bentur 2003). In the present study another kind of knitted structure, namely, weft knitted fabric (jersey), was used as reinforcement for fiberconcrete beams. This reinforcement is made out of glass fiber yarns. This kind of knitted structure was chosen because of their relative simplicity and low-cost; glass fiber yarns were chosen because of light weight and excellent cost/ performance ratio. The purpose of this research is to estimate the influence of glass knitted fabric layers on the flexural properties of fiberconcrete.

\section{Materials and Methods}

\subsection{Textiles}

In the present study dry relaxed fabric layers ( 3 in our case) with no significant pretension were used to reinforce fiberconcrete beams.

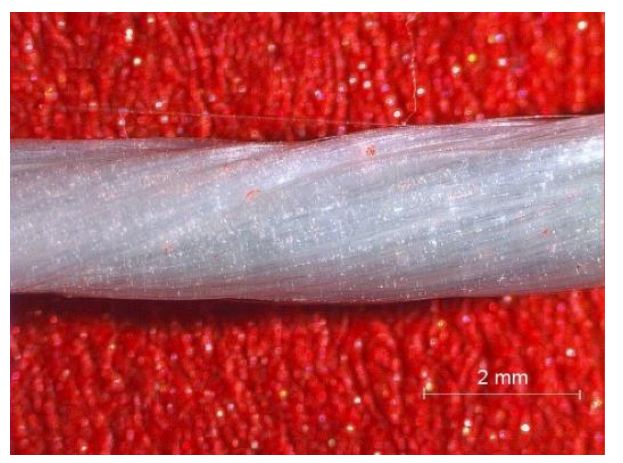

Fig. 1. Glass roving used in this study.

Reinforcement textile was a weft knitted fabric in a form of jersey knitted pattern (Fig. 2) produced manually. This textile was made using E-glass roving supplied by the Latvian company JSC "Valmiera Glass Fibre" (Fig. 1). 


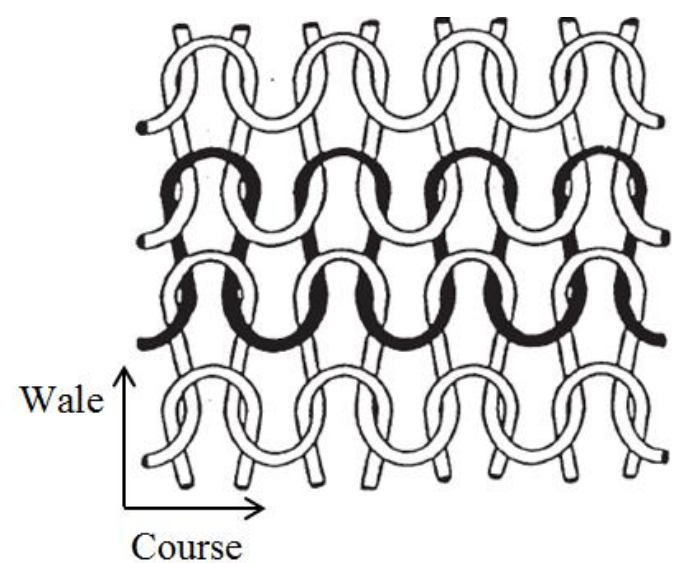

(a)

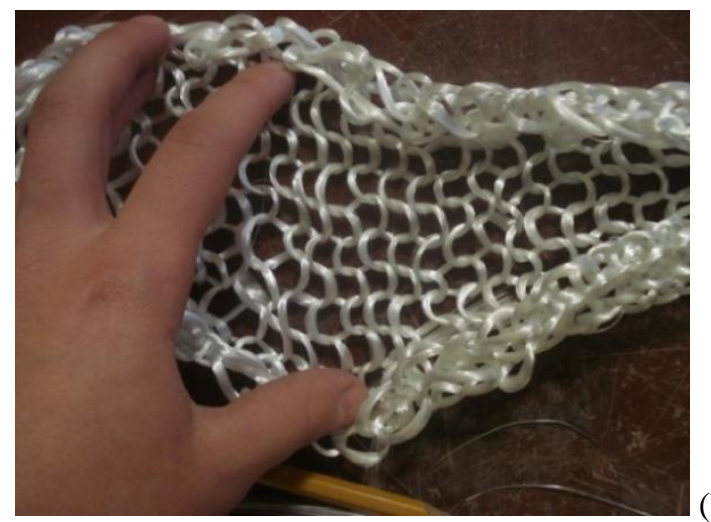

(b)

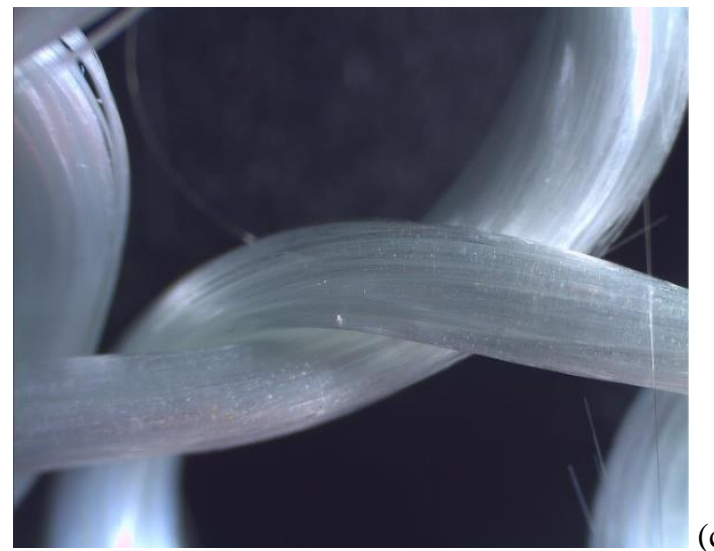

(c)

Fig. 2. Scheme of the weft knitted fabric structure - jersey (a) (Miravete 1999), textile layer used in this study (b) and fragment of loops crossover (c).

The glass knitted fabric used in this study is relatively loose. Roving had theoretical diameter equal to $1.1 \times 10^{3} \mathrm{~m}$ and linear density 2400 tex. The dimensions of the textiles were equal to the area of the used mould, namely, about $100 \mathrm{~mm}$ wide and $400 \mathrm{~mm}$ long and approximately 4-6 $\mathrm{mm}$ thick.

\subsection{Preparation of fiberconcrete beams}

Fiberconcrete beams reinforced by fabric reinforcement in the form of three unidirectional plies of weft knitted fabric (see section 1.1) were fabricated together with non- reinforced fiberconcrete samples with the goal to evaluate the influence of the textile reinforcement. Fabric wale direction coincides with the longer side of the fiberconcrete block. Preparation of samples was carried out in special molds, finally the beams having $100 \times 100 \times 400 \mathrm{~mm}$ dimensions were obtained. The concrete mixture proportions are shown in Table 1.

Table 1.Fiberconcrete mixture proportions.

\begin{tabular}{l|l}
\hline \multicolumn{1}{c|}{ Materials } & \multicolumn{1}{|c}{ Amount } \\
\hline Cement & $12.25 \mathrm{~kg}$ \\
Gravel $(4-8 \mathrm{~mm})$ & $28.14 \mathrm{~kg}$ \\
Sand $(0-1 \mathrm{~mm})$ & $3.115 \mathrm{~kg}$ \\
Sand $(0.3-2.5 \mathrm{~mm})$ & $18.76 \mathrm{~kg}$ \\
Dolomite powder & $2.87 \mathrm{~kg}$ \\
Microsilika & $1.155 \mathrm{~kg}$ \\
Water & $5.635 \mathrm{~kg}$ \\
Superlasticizer & $196 \mathrm{ml}$ \\
Dramix steel fibers $6 \mathrm{~mm}$ & $2.10 \mathrm{~kg}$ \\
\hline
\end{tabular}

Vibration was applied to the samples during the fabrication, to achieve a better penetration of the matrix in the openings of the knitted fabric. Individual fabrics layers were placed to the desired depth in the mould manually (Fig. 3) and were matured for 28 days. Thereafter, they were tested by the four point bending method.

\subsection{Flexural test}

Flexural strength of the fiberconcrete beams was determined by the third-point test according to ASTM C1609 Standard. The test was carried out with Controls Automax 5 testing machine until specimen failure. Four samples reinforced with knitted fabric plies and two non-reinforced beams were tested. Load was applied in $0.25 \mathrm{kN}$ steps. Load-deflection curves were recorded and flexural strength was calculated.

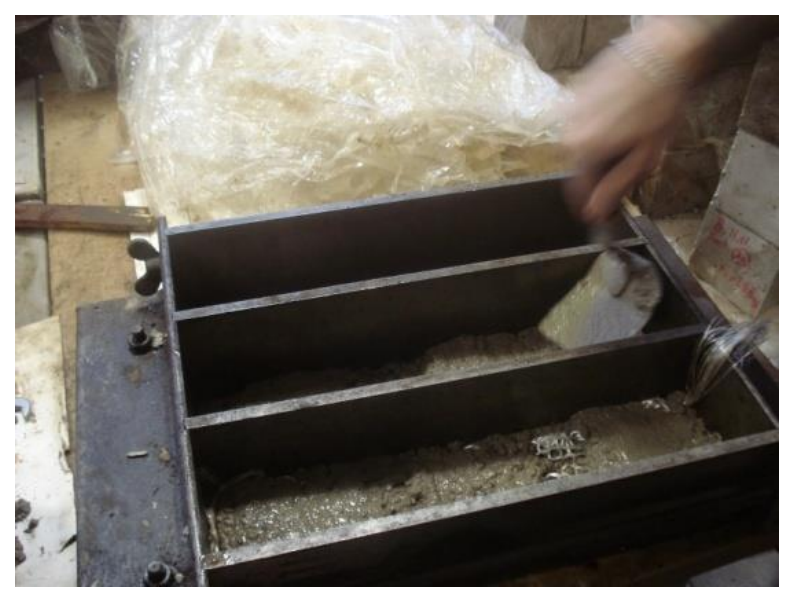

Fig. 3. Knitted textiles structures are laid at the desired level in the mould. 


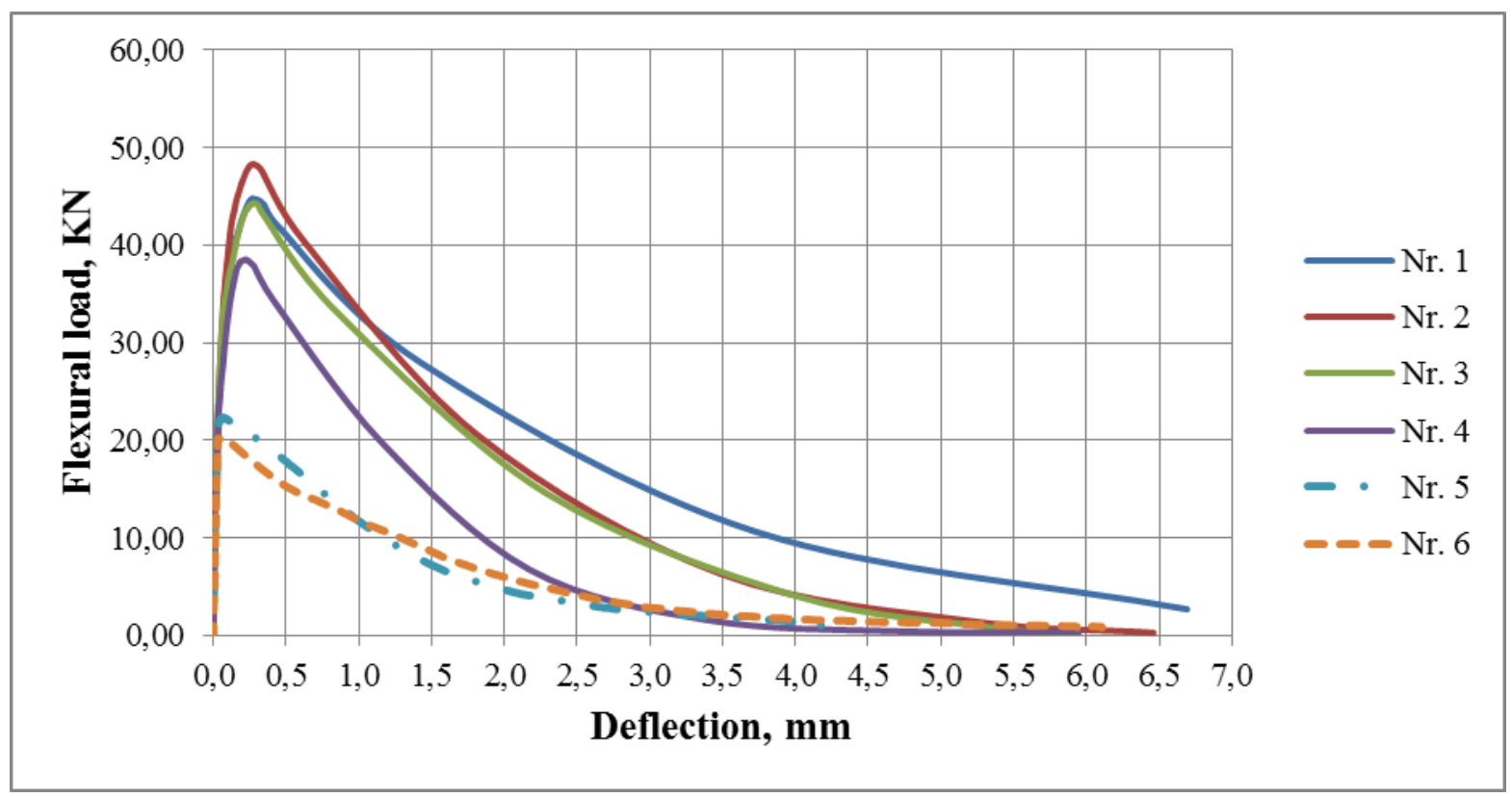

Fig. 4. Force-deflection curves: samples No.5 and 6 are samples without fabric reinforcement.

Broken samples were explored using optical microscopy with a goal to analyse the penetration of the matrix (fiberconcrete) to the glass yarns.

\section{Results and discussions}

The performance of the fiberconcrete with three layers of glass weft knitted fabric was evaluated by four point bending test. Sample load carrying capacity was 38$48 \mathrm{kN}$. Load-deflection curves are presented in Fig. 4. These graphs show the experimental curve of each specimen. It is possible to see the influence of the fabric reinforcement on the strength of the studied fiberconcrete beams. Three phases on load deflection curves can be excreted. The first phase is linear elastic deflection when the beam is deforming without visible crack openings, textile reinforcement is not fully loaded and does not bear any significant load; behaviour of all samples is similar. In the next phase curves slightly deviate from the straight line and reach the maximum load value. The second phase corresponds to the propagation of micro-cracks, their multiplication and growing. Comparing the curves for textile reinforced and non-reinforced samples we can conclude that at this stage textile layers begin to bear the load. The third phase corresponds to failure of the textile reinforcement; load-deflection curves of this stage are non-linear. For knitted fabric reinforced beams (samples No. 1-4) maximal flexural load is significantly larger (approximately twice as large) comparing with nonreinforced fiberconcrete samples (Nr. 5-6).

In Fig. 5 comparison is made between the flexural strength values for all samples.

Figure 6 shows the microscopic image of a glass knitted fabric in fiberconcrete matrix. The empty spaces in near-net textile were filled by concrete. This interaction and interlocking results lead to better adhesion between fibrous yarn and matrix and improve the ductility and energy absorption capacity of such kind of composites.

Visual and microscopical observations of failure surfaces showed two major reinforcement failure mechanisms - fiber rupture and pull-out of concrete matrix.

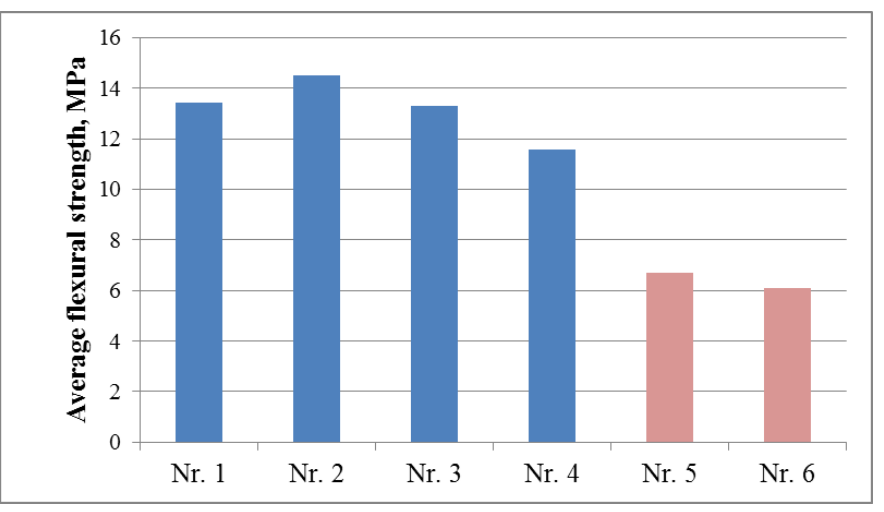

Fig. 5. Flexural strength values: samples No. 5 and 6 are samples without fabric reinforcement.

Although the sizing on the glass yarns (roving) partially prevents concrete matrix penetration deep inside the fiber bundle, a large number of fibers on the yarn "surface", covered by the concrete, allow good bonding between the yarn and matrix (Fig. 5), but the authors should mention that the coating of the fibers (yarns) may be detrimental from a bonding point of view, since only the perimeter of the yarn is in contact with the matrix. Glass roving used in this study during glass fibers production process had silane coating (according to the manufacturer). 

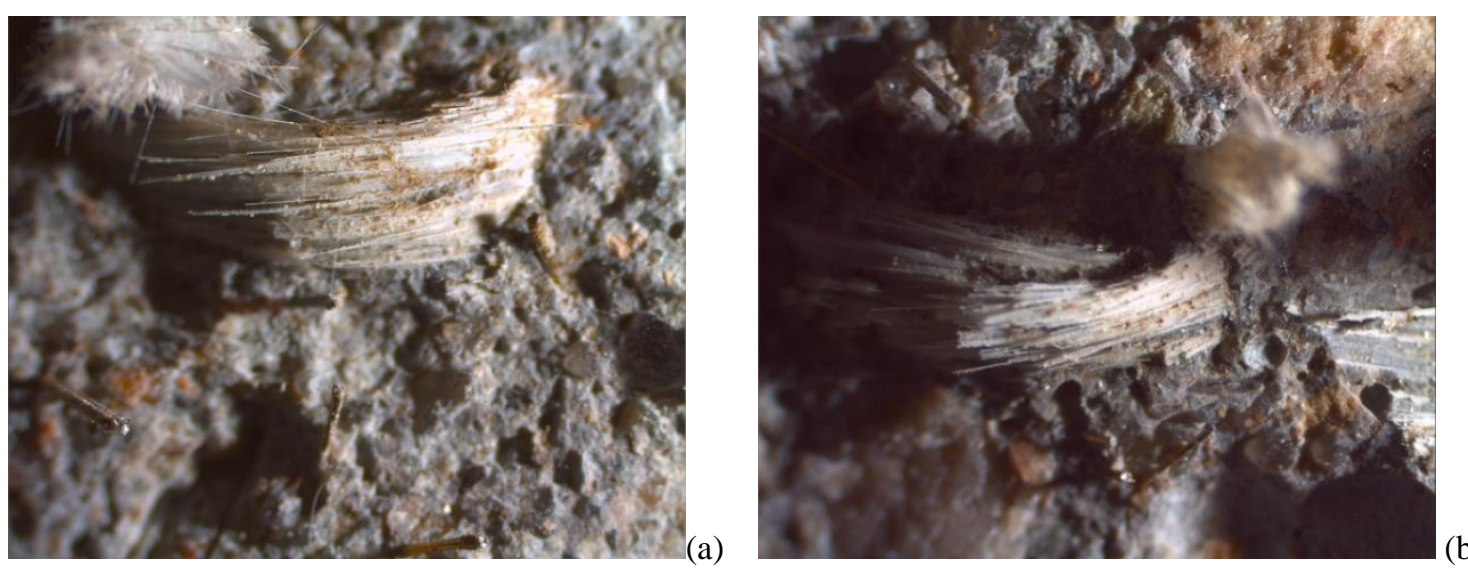

(b)

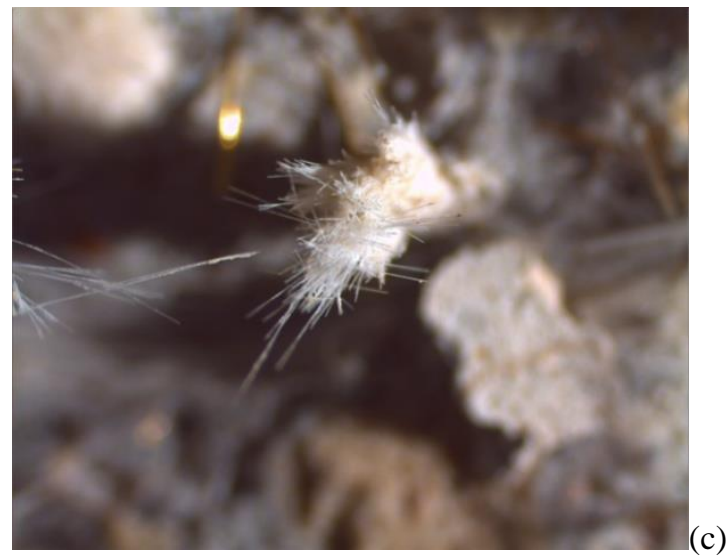

Fig. 5. Optical microscopy photography: $\mathrm{a}$ - fragment of loop penetrated in the fiberconcrete matrix, $\mathrm{b}$ - partly broken yarn in the loop head zone, $\mathrm{c}$ - fully ruptured yarn.

Reinforcing concrete and fiberconcrete with knitted fabrics, which have high degree of flexibility and good drape ability, have high application potential in shells and spatial (non-flat) constructions. If the volume content of the textile reinforcement is large enough, it carries load also after the matrix has cracked, therefore cracking process will not be catastrophic, and the composite could sustain additional loads and deformations, and it should be noted that the cement composites have certain critical volume content.

Manual fabrication of textiles can be a time-consuming process, therefore it is better to use knitting machines, but in the case of traditional textile machines maximal yarn diameter is limited, as well as the appropriate size of loops.

At this moment, concrete and fiberconcrete reinforcing with textiles can be done manually, and that limits the size of construction details and can lead to deviations in mechanical properties; another possibility is pultrusion process (Peled et al. 2008).

\section{Conclusions}

In this study fiberconcrete beams with three layers of weft knitted fabric made from glass roving were fabricated and tested with four point bending test. The obtained results were compared with fiberconcrete samples without textile reinforcement.
Regarding results of this investigation, the following conclusions can be made:

- Concrete and fiberconcrete can be successfully reinforced by weft knitted fabric and its layers made of glass fiber yarns.

- Experimental bending tests had shown improvement of flexural strength parameters comparing with nonreinforced fiberconcrete.

Knitted fabric reinforced concrete and fiberconcrete have high application potential in spatial constructions with small thickness. More studies are needed to estimate the effects and influence of different textile architecture and geometrical parameters, materials and number of layers, as well as textile orientation on the flexural properties of fiberconcrete. The authors would like to point out that the types of coating used during yarn and textile fabrication process can affect bonding.

\section{References}

ACI Committee 544. 1997. State-of-the-Art Report on Fiber Reinforced Concrete (ACI 544.1R-96). American Concrete Institute, Farmington Hills, Mich, 66 p.

Contamine, R.; Si, Larbi, A.; Hamelin, P., 2013. Identifying the contributing mechanisms of textile reinforced concrete (TRC) in the case of shear repairing damaged and reinforced concrete beams. Engineering Structures, 46, pp. 447-458. http://dx.doi.org/10.1016/j.engstruct.2012.07.024 
Krüger, M.; Reinhardt, H.-W.; Fichtlscherer, M., 2001. Bond behaviour of textile reinforcement in reinforced and prestressed concrete. Otto-Graf-Journal, 12, pp. 33-50.

Leong, K.H.; Ramakrishna, S.; Huang, Z.M.; Bibo, G.A., 2000. The potential of knitting for engineering composites-a review. Composites, Part A31, pp. 197-220. http://dx.doi.org/10.1016/S1359-835X(99)00067-6

Miravete, A. (Ed.), 1999. 3-D Textile Reinforcements In Composite Materials. CRC Press 1999. 181 p.

Pakravan, H.; Jamshidi, M.; Latifi, M.; Neshastehriz, M., 2011. Application of polypropylene nonwoven fabrics for cement composites reinforcement. Asian journal of civil engineering (building and housing), 12(5), pp. 551-562.

Peled, A.; Bentur, A., 1998. Reinforcement of cementitious matrices by warp knitted fabrics. Materials and Structures, 31, pp. 543-550. http://dx.doi.org/10.1007/BF02481536

Peled, A.; Bentur, A., 2000. Geometrical characteristics and efficiency of textile fabrics for reinforcing cement composites. Cement and Concrete Research, 30, pp. 781-790.

http://dx.doi.org/10.1016/S0008-8846(00)00239-8
Peled, A.; Bentur A., 2003. Fabric structure and its reinforcing efficiency in textile reinforced cement composites. Composites, Part A, 34, pp. 107-118. http://dx.doi.org/10.1016/S1359-835X(03)00003-4

Peled, A.; Cohen, Z.; Pasder, Y.; Roye, A.; Gries, T., 2008. Influences of textile characteristics on the tensile properties of warp knitted cement based composites. Cement \& Concrete Composites, 30, pp. 174-183.

http://dx.doi.org/10.1016/j.cemconcomp.2007.09.001

Peled, A.; Mobasher, B.; Cohen, Zvi., 2009. Mechanical properties of hybrid fabrics in pultruded cement composites. Cement \& Concrete Composites, 31, pp. 647-657.

http://dx.doi.org/10.1016/j.cemconcomp.2009.06.002

\section{Acknowledgements}

This work has been supported by the European Social Fund within the Project No. 2013/0025/1DP/1.1.1.2.0/13/ APIA/VIAA/019 "New "Smart" Nanocomposite Materials for Roads, Bridges, Buildings and Transport Vehicle". 